\title{
New Cation-Exchange Membranes for Hyperfiltration Processes
}

\author{
P. M. VAN DER VELDEN* and C. A. SMOLDERS, Twente University of \\ Technology, Enschede, The Netherlands
}

\begin{abstract}
Synopsis
A new route for the preparation of cation exchange membranes from polystyrene-polyisoprenepolystyrene (SIS) block copolymers has been studied, using $\mathrm{N}$-chlorosulfonyl isocyanate. At temperatures of $0^{\circ}$ to $20^{\circ} \mathrm{C}, \mathrm{N}$-chlorosulfonyl isocyanate reacts readily with the olefin group in polyisoprenes, resulting in a $\beta$-lactam- $\mathrm{N}$-sulfonyl chloride group. Films of this product can be cast which are hydrolyzed afterwards with aqueous ammonia at room temperature to give a membrane with ionic sulfonate and neutral carbamoyl groups. Homogeneous membranes are prepared with an SIS block copolymer as starting material and with mole ratios of $\mathrm{N}$-chlorosulfonyl isocyanate/isoprene between $15 \%$ and $45 \%$. In hyperfiltration experiments at 40 atmospheres, both $\mathrm{NaCl}$ and $\mathrm{Na}_{2} \mathrm{SO}_{4}$ are rejected up to $82 \%$, while fluxes of 0.25 to $0.30 \mathrm{~cm}^{3} / \mathrm{cm}^{2} \cdot \mathrm{hr}$ are obtained. From permeation and hyperfiltration experiments, it is concluded that the weight fraction of membrane water has a large influence on the flux. The water content in the membrane during the hyperfiltration process is primarily determined by the applied pressure, the type of salt, and its concentration.
\end{abstract}

\section{INTRODUCTION}

In the last few years, different ionic membranes have been described for use in hyperfiltration (reverse osmosis) experiments. Ionic membranes reject salt by the presence of a Donnan potential at the interface membrane/feed solution. The magnitude of this Donnan potential results from the effective charge density in the membrane, which is determined by the ion exchange capacity and by the volume fraction of membrane water under operation conditions. ${ }^{1}$

One of the major problems in the use of ion exchange membranes concerns their sensitivity for ion pair formation between the fixed ionic groups and polyvalent counterions in solution, resulting in a decrease in the effective charge density. ${ }^{2}$ Especially, the weakly acid carboxylate group is strongly sensitive to ion pair formation with $\mathrm{Ca}^{2+}$ and $\mathrm{Mg}^{2+}$ ions, whereas strongly acid sulfonate groups are less sensitive to poisoning. For that reason, cation exchange membranes are prepared on a large scale by sulfonation. Usually, sulfuric acid, sulfur trioxide, and chlorosulfonic acid are used ${ }^{3-7}$ as sulfonating agents. The work reported here is a study on the preparation and properties of cation exchange membranes containing sulfonate groups, introduced by $\mathrm{N}$-chlorosulfonyl isocyanate as a modifying agent for isoprene-containing polymers.

In order to obtain a high rejection value, the effective charge density should be as high as possible. At higher charge densities, however, the volume fraction

* Present address: Cordis Dow B.V., Roden, The Netherlands. 
of membrane water increases and can cause problems with respect to the mechanical strength of the membranes. Several methods have been applied in order to prevent this problem. Van Heuven and Bloebaum ${ }^{8}$ described the use of chemically crosslinked ion exchange particles in dynamically formed cation exchange membranes. Yasuda, Lamaze, and Schindler ${ }^{9}$ and Yasuda and Schindler ${ }^{7}$ introduced these crosslinks by graft polymerization on hydrophobic polymer films. Lopatin and Newey ${ }^{6}$ and Yasuda et al. ${ }^{7,9}$ used physical crosslinks of uncharged domains in membranes made from block copolymers. In this study, we used a physically crosslinked membrane. As a starting material for the membrane preparation, a commercially available polystyrene-polyisoprenepolystyrene (SIS) block copolymer (CARIFLEX TR 1108) was used. A study was made of the overall hyperfiltration properties of these membranes and of possible deswelling phenomena under actual use (influence of applied pressure and salt concentration).

\section{EXPERIMENTAL}

\section{Synthesis of the Polyelectrolytes}

A polystyrene-polyisoprene-polystyrene (SIS) block copolymer can be modified according to Van der Does, Hofman, and Van Utteren. ${ }^{10}$ These authors investigated the reaction between polyisoprene and $\mathrm{N}$-chlorosulfonyl isocyanate in toluene to form an uncharged intermediate (I):<smiles>CCC=C(C)C=CCC1C(=O)N([S+](=O)(=O)Cl)C1(C)CCCCC</smiles>

Hydrolysis of polymer I with a $2 \mathrm{~N} \mathrm{NaOH}$ solution at $100^{\circ} \mathrm{C}$ resulted in a polyelectrolyte (II) with both carboxylate and sulfonate groups:<smiles>CCCCCCCC(C)(N[SH](=O)[O-])C(=O)O[NH3+]</smiles>

II

Membranes prepared from polymer II, containing a carboxylate group, are very sensitive to changes of $\mathrm{pH}$ in the range of $\mathrm{pH}$ values 4 to 8 and have large sensitivity toward polyvalent counterions.

For these reasons and the fact that a postpolymer reaction at $100^{\circ} \mathrm{C}$ can give problems in practice, we did not hydrolyze polymer I with aqueous $\mathrm{NaOH}$ but 
with aqueous ammonia. The hydrolysis reaction was carried out with $1.65 \mathrm{~N}$ ammonia at room temperature. The reaction product formed during this reaction has the following structure: ${ }^{11}$<smiles>CCC=C(C)C=CCC(C(N)=O)C(C)(CC)N[SH3+]</smiles>

III

The final reaction product III, when starting with an SIS block copolymer, is indicated as SISS- $x$, where $x$ (in \%) stands for the ratio of the number of moles of $\mathrm{N}$-chlorosulfonyl isocyanate added to the number of moles isoprene units present in the polymer.

However, since the modifying agent does not react quantitatively, $x$ does not give the real degree of substitution. Van der Does ${ }^{12}$ found, for dilute polymer solutions in toluene, that the actual degree of substitution $(a)$ in the SIS analogue of polymer I was about $0.7 x$. Using more concentrated polymer solutions, we found for SISS-20.0 and SISS-28.3 polymers, prepared at $0^{\circ} \mathrm{C}$, by titration ion exchange capacities of 1.10 and $1.47 \mathrm{meq} / \mathrm{g}$, respectively.

Since the block copolymer used contains $29 \%$ polystyrene, the ion exchange capacity $\left(C_{d}^{*}\right)$ for the SISS- $x$ polymers is given by

$$
C_{d} *=\frac{10 a}{94+1.57 a} \mathrm{meq} / \mathrm{g} \text { polymer }
$$

With this equation, we can calculate that the experimental I.E.C. values given above are in agreement with the data found by Van der Does.

\section{Membrane Preparation}

Membranes were prepared from the SIS analogue of polymer I (SISL- $x$ ). Since membrane performance depends strongly on membrane morphology, it is important to control the latter property. For both ways of preparing membranes, viz., by evaporation and by coagulation, it is an advantage that the nonionic intermediate product I can be used while fixing the membrane structure. From a $10 \%$ SISL- $x$ solution in toluene, a film was cast on a glass plate with a doctor's knife.

After evaporation of the toluene (90 min), the film was hydrolyzed in $1.65 \mathrm{~N}$ ammonia. The time required for completion of the reaction with ammonia was determined from the disappearance of the absorption peak at $1810 \mathrm{~cm}^{-1}$ in the infrared spectrum (Fig. $1 \mathrm{~b}$ and c). A reaction time of $45 \mathrm{~min}$ was used since the $1810 \mathrm{~cm}^{-1}$ absorption peak had disappeared completely within $30 \mathrm{~min}$ (Fig. 1c); after the film was rinsed with water, it was ready for use.

\section{Determination of Water Content}

Weight fractions of membrane water were determined by immersion and by thermogravimetric analysis (du Pont TGA-950). 


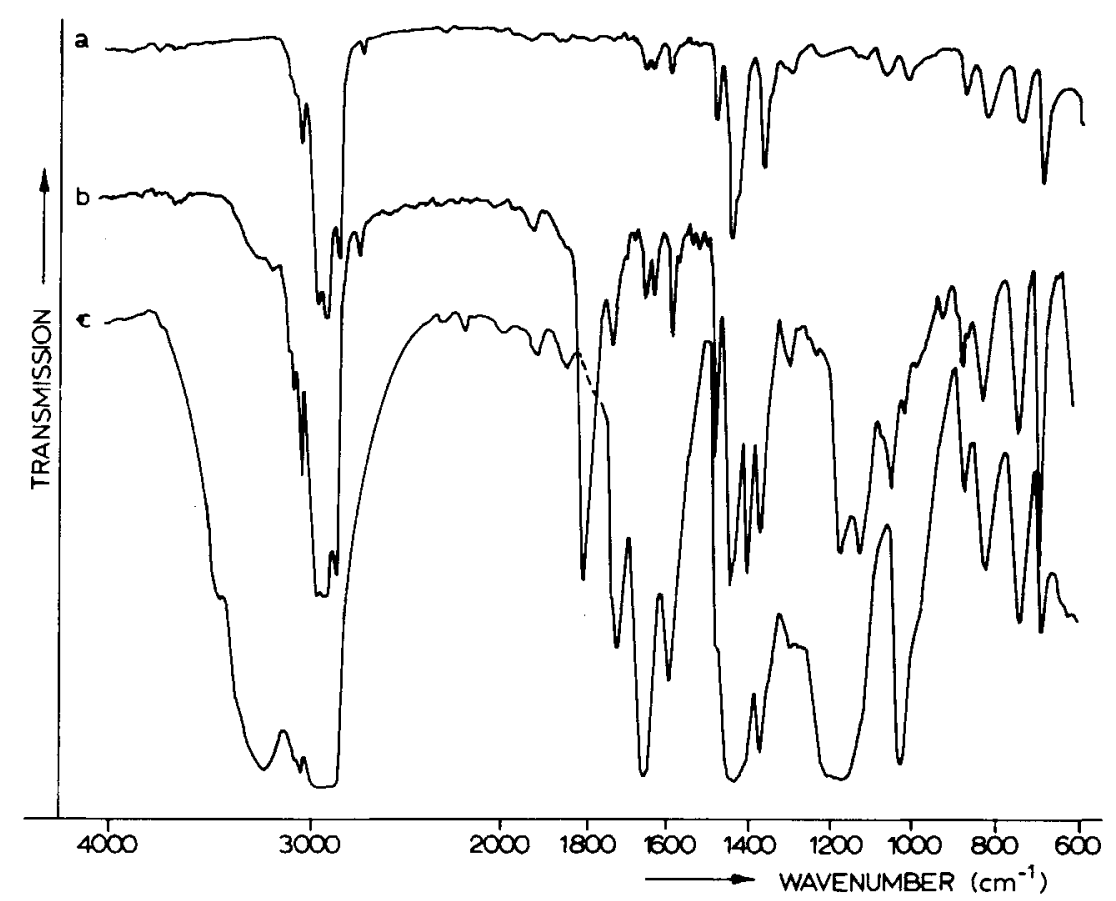

Fig. 1. Infrared spectra from CARIFLEX TR 1108 (a) and the SIS analogues I (b) and III (c).

For the immersion method, the films were equilibrated in water, carefully wiped with filter paper, weighed, vacuum dried at $50^{\circ} \mathrm{C}$, and weighed again. For the TGA method, the films were handled in the same way as for the immersion method, except for vacuum drying. Samples were then studied at different heating rates $(2-15 \% / \mathrm{min})$ with a stream of nitrogen gas passing over.

\section{Hyperfiltration Experiments}

The experiments were performed with three different test units. Two of these units were Amicon pressure cells (Type 420 for high pressures and Type $401 \mathrm{~S}$ for low pressures) connected with a reservoir. These cells are part of a noncirculating system held under nitrogen pressure.

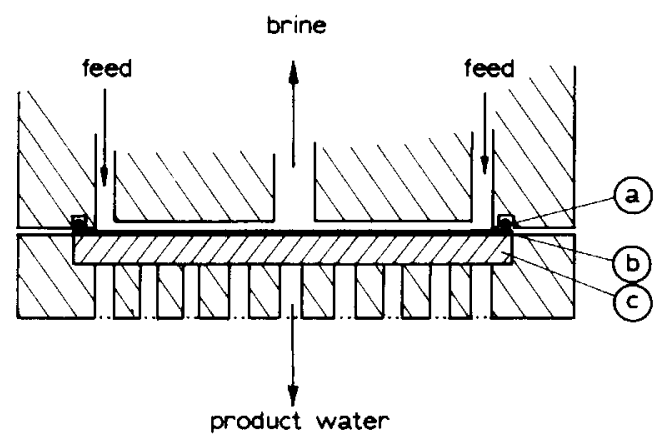

Fig. 2. High-pressure hyperfiltration cell: (a) O-ring; (b) membrane; (c) porous disk. 
The feed solution in the cell is stirred at 450 rotations per minute by means of a magnetic stirrer directly above the membrane. The third unit consisted of a closed hyperfiltration circuit, incorporating five flat cells (Fig. 2), a membrane pump, and a cooling spiral. Rejections were determined by measuring the salt concentration conductometrically:

$$
R_{\text {observed }}=\frac{C_{\text {feed }}-C_{\text {permeate }}}{C_{\text {feed }}} \times 100 \%
$$

All experiments were carried out at $24^{\circ} \pm 2^{\circ} \mathrm{C}$.

\section{RESULTS AND DISCUSSION}

\section{Water Content as Function of Degree of Substitution}

Water contents of SISS- $x$ films with different degrees of substitution were determined. In those cases where $x>65 \%$, SISL- $x$ films could not be prepared, since these films were extremely brittle (Fig. 3). In Figure 4, the weight fraction of water in the polymer, $H^{*}$, is plotted as a function of $x$.

The SISS- $x$ polymers with $x>40 \%$ were highly swollen and could not be used as membranes for hyperfiltration because of lack of mechanical strength. Obviously, at degrees of substitution higher than $x=40 \%$, the physical crosslinks, formed by polystyrene domains in the material, cannot prevent swelling to an inacceptably high level. Hence, we only studied the transport properties through membranes for $x$ values from $20 \%$ up to $40 \%$.

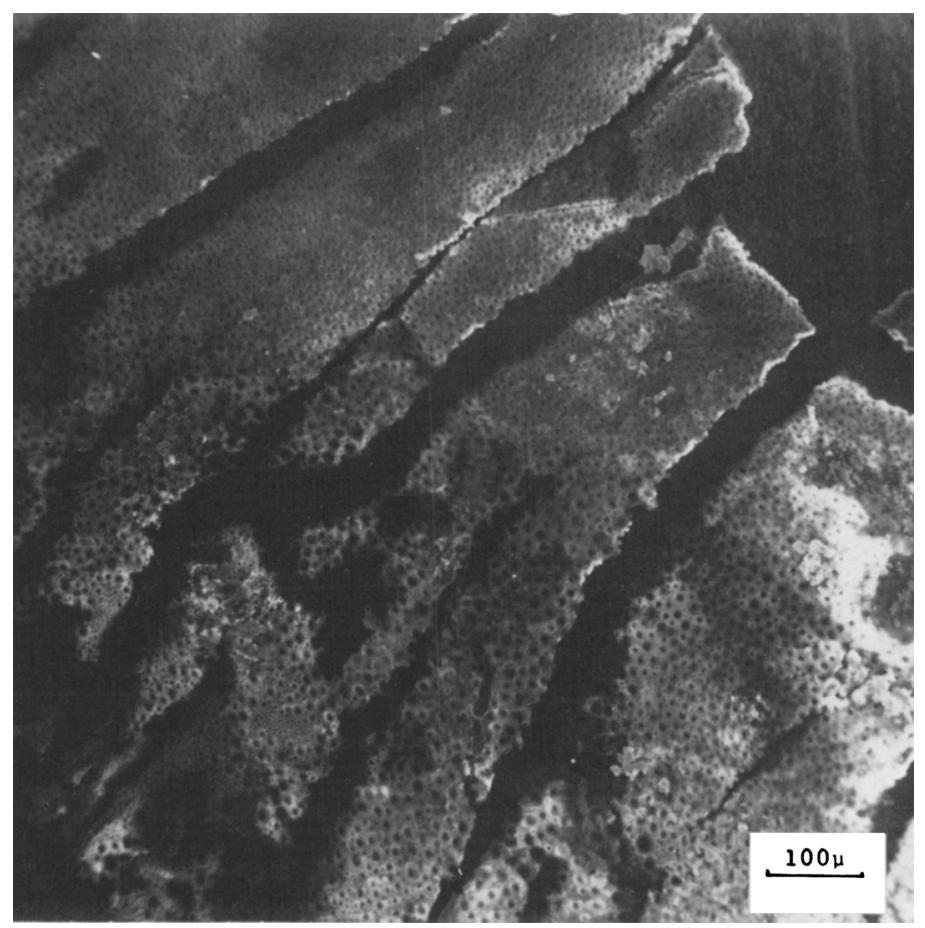

Fig. 3. Film cast from a SISL-80 solution in toluene (SEM photo made after carbon and alumina deposition). 


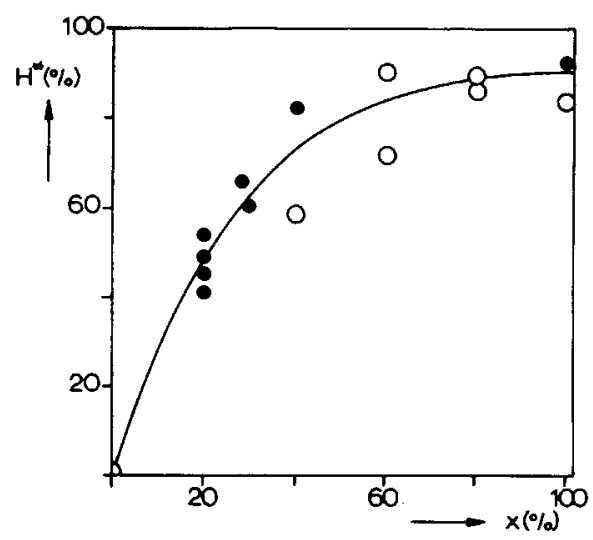

Fig. 4. Weight fraction of water in various SISS- $x$ samples: (O) TGA measurements; (๑) immersion measurements.

Homogeneous membranes prepared from SISS- $x$ polymers with degrees of substitution lower than $x=20 \%$ were not studied, since the fluxes through these membranes were very small.

\section{Water Transport Through SISS-x Films}

Water transport through swollen films can be either diffusive or a combination of diffusive and viscous flow. This depends to a large extent on the mode of hydration. In weight fractions of water as found in SISS- $x$ films (Fig. 4), both water of hydration and bulk water will be present.

Figures 5 and 6 show, in combination with Table I, that when the feed solution contains no solutes, the transport of water through swollen SISS- $x$ films at different pressures $(p)$ is not linear with $p$. This phenomenon was also observed by other authors. ${ }^{13-15}$

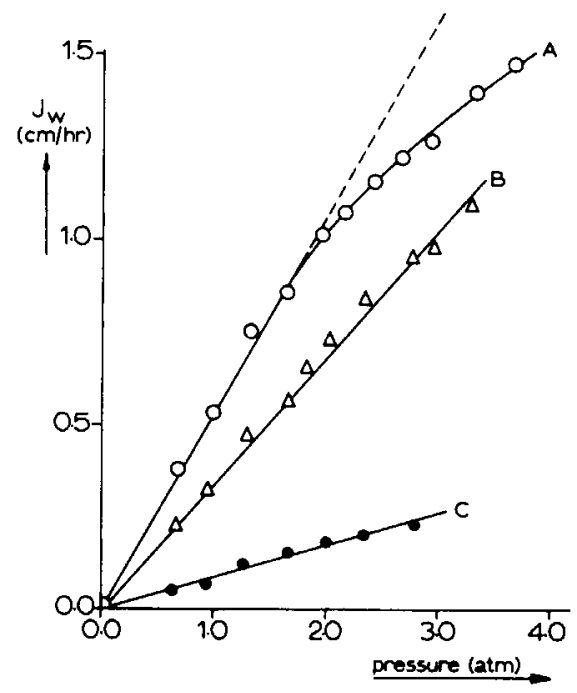

Fig. 5. Flux through SISS- $x$ membranes at low pressures (A, B and C refer to Table I). 
TABLE I

Water Content for Three Different SISS- $x$ Membranes

\begin{tabular}{clccc}
\hline $\begin{array}{c}\text { Membrane } \\
\text { no. }\end{array}$ & Membrane & $\begin{array}{c}\text { Dry membrane } \\
\text { thickness, } \mu\end{array}$ & $H^{*}, \%$ & $\begin{array}{c}\text { Time stored in } \\
\text { water after } \\
\text { hydrolysis, hr }\end{array}$ \\
\hline A & SISS-28.3 & 35 & 80.4 & 72.00 \\
B & SISS-28.3 & 35 & 66.5 & 0.05 \\
C & SISS-20 & 46 & 41.0 & 2.45 \\
\hline
\end{tabular}

If the water content did not change with increasing pressure, the flux should be given by

$$
J_{w}=K_{1}(p-\Delta \pi)
$$

and with pure water, $J_{w}$ should be linear in $p$. Yasuda et al. ${ }^{7,16,17}$ considered the influence of the volume fraction of membrane water on the flux, which resulted in the equation

$$
K_{1}=K_{0} \cdot \exp \left[-B\left(\frac{1-H}{H}\right)\right]
$$

where $H$ could be a function of $p$. Yasuda et al. ${ }^{16}$ found that the slope in the plot of flux versus pressure was linear, which indicated that for the pressures concerned, $H$ was independent of $p$. Whenever the plot was not linear, the initial slope was used for the calculation of $K_{1}$.

As a result of this approach, $B$ was calculated by using $H_{0}$ instead of $H$ in eq. (4); $B$ appeared to be 1.32. It is doubtful, however, whether the replacement of $H$ by $H_{0}$ is always correct for membranes under hyperfiltration conditions.

Katchalski ${ }^{18}$ showed that for small changes in the weight fraction of water of hydration, eq. (5) is valid:

$$
H=H_{0}-K_{2} p
$$

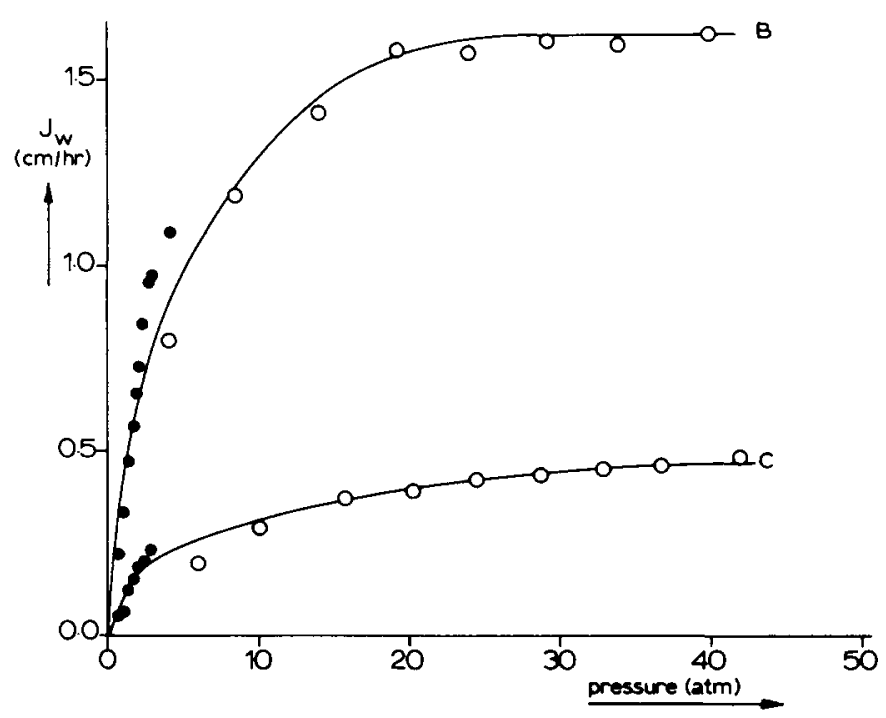

Fig. 6. Flux through SISS- $x$ membranes at high pressures (B and C refer to Table I). 


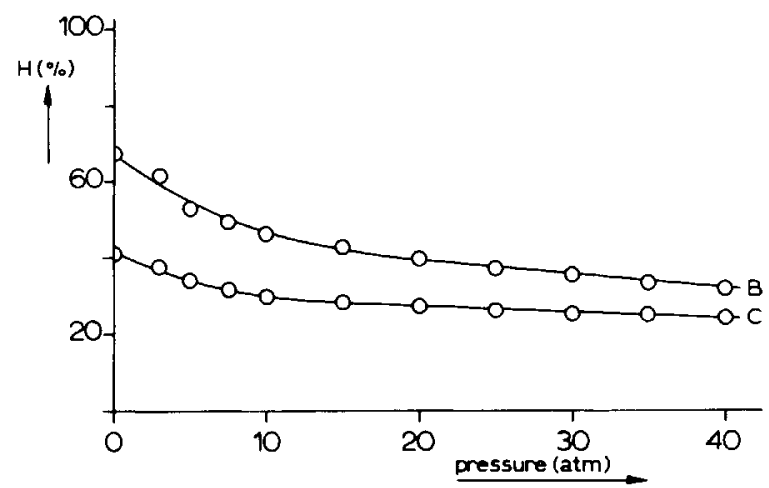

Fig. 7. Decline in weight fraction of membrane water at different pressures as approximated by eq. (7) (B and C refer to Table I).

This equation can be rewritten by a truncation of a binomial series:

$$
\frac{1-H}{H}=\frac{1-H_{0}}{H_{0}}+\frac{\Delta}{H_{0}}
$$

where $\Delta$ is the fractional deswelling $K_{2} p / H_{0}$. Equation (6) shows that only when $\Delta$ is small compared with $H_{0}$, the replacement of $H$ by $H_{0}$ is correct.

The water transport through both SISS-20 en SISS-28.3 films was studied by measuring the flux with pure water as feed. The experimental results given in Table I and Figure 5 show that the water content of SISS-28.3 films increases when the films are kept in water. Deviation of a linear $J_{w}-p$ relation is observed already at low pressures for high $H_{0}$ values. At higher pressures (Fig. 6), all $J_{w}-p$ curves become nonlinear. By extrapolation of the linear part of the $J_{w}-p$ curves to higher $p$ values, the deswelling can be calculated with the aid of eq. (7):

$$
\ln \left\{\frac{J_{w} \text { (linear) }}{J_{w} \text { (experimental) }}\right\}=B\left[\frac{1-H}{H}-\frac{1-H_{0}}{H_{0}}\right]
$$

In Figure $7, H$, as calculated by eq. (7), is plotted as a function of the applied pressure for the curved lines in Figure 6, assuming $H_{0}$ and $H_{0}{ }^{*}$ to be equal. The result is qualitatively in agreement with Katchalski's equation ${ }^{18}$ for the volume change of a swollen polyelectrolyte gel and with other compression data for comparable cation exchange membranes based on the same SIS polymer. ${ }^{6}$

\section{Transport of Water Vapor Through SISS-x Films}

In general, water of hydration and loosely bound bulk water can be distinguished. The deswelling mentioned above is due to the partial removal of loosely bound bulk water. The amount of water of hydration in a nonswollen membrane, however, influences the magnitude of the water transport through the membrane under a vapor pressure gradient. Therefore, the water transport through SISS- $x$ films was studied under an applied difference of water vapor pressure across the membrane.

All experiments were carried out in a Stanton thermobalance by measuring the weight decrease of the cell as a function of time at a temperature of $22.5^{\circ} \pm$ $0.5^{\circ} \mathrm{C}$; the atmosphere in the thermostated chamber of the Stanton balance was 


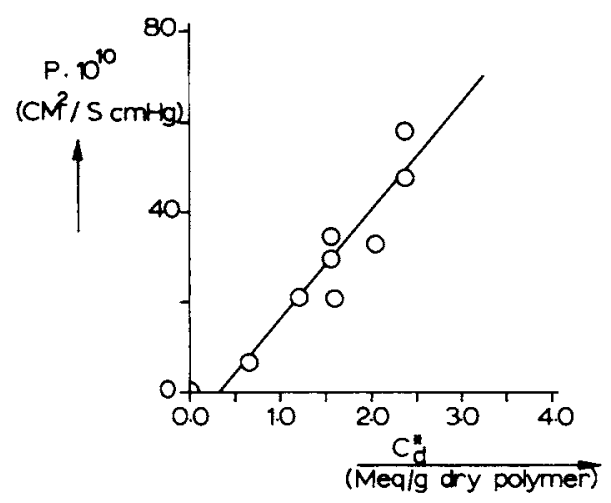

Fig. 8. Permeation coefficient of water through SISS- $x$ films.

circulated during the experiments to keep the relative humidity at $56 \%$. The nonswollen SISS- $x$ films separated two compartments with equal total pressures, but with relative humidities of $56 \%$ and $100 \%$, respectively. Permeation coefficients were calculated by

$$
J=P \frac{\Delta p}{l}
$$

In Figure 8, the permeation coefficients $P$ are plotted against $C_{d} * ; C_{d}$ * was calculated on the base of $65 \%$ effective substitution, using eq. (1). From these results, we can see that $P$ increases linearly with $C_{d} *$. This result indicates that the amount of water of hydration and the diffusive water transport through the membrane increase linearly with the concentration of ionic and polar groups.

The straight line in Figure 8, however, does not pass through $C_{d} *=0$. This observation can be explained by comparing these data with those for viscous flow through swollen membranes. Yasuda et al. ${ }^{17}$ showed that viscous flow is opposed by frictional resistance of the macromolecules. At a critical swelling $H_{c}$, however, there are enough permeant molecules to allow viscous flow. On the analogy of this phenomenon, it may be assumed that the nature of the diffusive transport changes abruptly at some critical value of $C_{d} *$ above which perhaps a continuous water phase forms between some if not all of the hydration centers.

\section{Hyperfiltration Experiments on SISS-x Membranes}

The SISS- $x$ membranes with $x=20 \%, 28.3 \%, 30 \%$, and $40 \%$ were tested with sodium chloride solutions in an Amicon high-pressure cell. The rejection of $\mathrm{Na}_{2} \mathrm{SO}_{4}$ was studied with a SISS-20 membrane. The results of these tests are shown in Table II. The results obtained by using a closed-circuit hyperfiltration cell showed higher flux and rejection data. This difference may be due to the lower salt concentration used in the closed-circuit experiments, as well as the aggravation of concentration polarization in the Amicon cell.

Strathmann ${ }^{19}$ studied the influence of the stirrer velocity on the concentration polarization in a stirred cell and showed that concentration polarization increases quickly with decreasing stirrer velocity. In order to separate between the effect of both salt concentration and concentration polarization on the observed salt 
TABLE II

Hyperfiltration Results with Cation Exchange SISS- $x$ Membranes at 40 atm

\begin{tabular}{cclccc}
\hline $\begin{array}{c}\text { Hyperfiltration } \\
\text { apparatus }\end{array}$ & $\boldsymbol{x}$ & \multicolumn{1}{c}{ Feed solution } & $\begin{array}{c}\text { Pressure, Rejection, } \\
\text { atm }\end{array}$ & $\begin{array}{c}\text { Flux } \\
\mathbf{c m} / \mathbf{h r}\end{array}$ \\
\hline Amicon-420 & 20 & $0.078 \mathrm{~N} \mathrm{NaCl}^{2}$ & 40 & 65 & 0.15 \\
& & $0.054 \mathrm{Na}_{2} \mathrm{SO}_{4}$ & 40 & 82 & 0.25 \\
& & $0.054 \mathrm{~N} \mathrm{Na}_{2} \mathrm{SO}_{4}$ & 30 & 80 & 0.22 \\
& & water & 40 & - & 0.47 \\
& 28.3 & $0.078 \mathrm{~N} \mathrm{NaCl}$ & 40 & 42 & 0.40 \\
& 40 & water & 40 & - & 1.64 \\
Closed circuit & $0.078 \mathrm{~N} \mathrm{NaCl}$ & 40 & 36 & 0.62 \\
& 20 & $0.040 N \mathrm{NaCl}$ & 40 & 82 & 0.27 \\
& 30 & $0.040 N \mathrm{NaCl}$ & 40 & 52 & 1.29 \\
& 40 & $0.040 N \mathrm{NaCl}$ & 40 & 50 & 1.59 \\
\hline
\end{tabular}

rejection, we studied the influence of the salt concentration in the feed on the observed rejection $\left(R_{\text {obs }}\right)$ at constant stirrer velocity $(\omega=450 \mathrm{rpm})$. The experiments were carried out with a SISS-28.3 membrane in an Amicon highpressure cell. In agreement with Thomas, ${ }^{20} \ln \left(1-R_{\text {obs }}\right)$ was linear with the natural logarithm of the sodium chloride concentration in the feed solution.

Shorr et al. ${ }^{1}$ have given a relation between rejection and some ionic membrane parameters, which can be written as follows:

$$
(1-R)\left[\frac{C^{*}}{C_{\text {feed }}}+z(1-R)\right]^{z} \cdot \Gamma^{z+1}=z^{z}
$$

According to eq. (9), the rejection should increase with increasing $C^{*}$, decreasing $C_{\text {feed }}$, or increasing $z$. The results shown in Table II and Figure 9 are in agreement with eq. (9).

From the flux results measured at low pressures with pure water we can calculate $K_{0}$, since $H=H_{0}$. With the use of this $K_{0}$ value, the actual amount of membrane water can be calculated for the high-pressure experiments (Table III). The values for the actual amount of membrane water shown in Table III

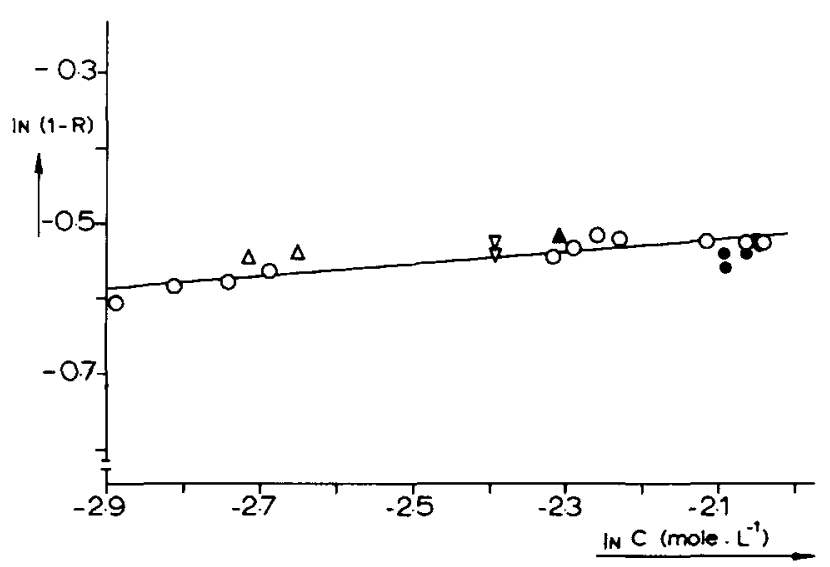

Fig. 9. Dependence of rejection of sodium chloride on the salt concentration for an SISS-28.3 membrane. 
TABLE III

Calculated Water Contents in SISS- $x$ Membranes Under Operation

\begin{tabular}{llcl}
\hline Membrane & \multicolumn{1}{c}{ Feed } & Pressure, atm & $H, \%$ \\
\hline SISS-20 & water & 2 & 45.5 \\
& water & 40 & 26.6 \\
SISS-28.3 & $0.078 N \mathrm{NaCl}$ & 40 & 22.1 \\
& water & 2 & 60.6 \\
& water & 40 & 30.7 \\
& $0.078 \mathrm{~N} \mathrm{NaCl}$ & 40 & 23.5 \\
\hline
\end{tabular}

give evidence for the fact that deswelling of ionic membranes is determined by both the applied pressure and by the salt concentration.

\section{Membrane Stability}

The stability of the membranes is primarily determined by the degree of swelling. ${ }^{6}$ When the reaction between SIS and N-chlorosulfonyl isocyanate in toluene was carried out at a reaction temperature of $20^{\circ} \mathrm{C}$ and the films were kept in water, SISS- $x$ membranes with $x=30 \%$ and $40 \%$ showed degradation within one day. During the hyperfiltration tests, these membranes showed a decrease of the observed rejection already after $1 \mathrm{hr}$ from startup. When the reaction temperature was lowered to $0^{\circ} \mathrm{C}$, it was possible to produce membranes which were stable under hyperfiltration conditions (SISS-28.3), or both under hyperfiltration conditions and during longer periods at room temperature in water. After three days, SISS-20 membranes still showed no change in the membrane performance. Van der Does et al. ${ }^{12}$ showed that the viscosity increased for SISS- $x$ solutions prepared at lower reaction temperatures. Hence, the difference in stability between SISS- $x$ membranes made at reaction temperatures of zero and $20^{\circ} \mathrm{C}$, respectively, might be due to cleavage of the polyisoprene chain in the polymer at higher reaction temperatures.

\section{CONCLUSIONS}

From the results given above, it can be concluded that $\mathrm{N}$-chlorosulfonyl isocyanate can be used to modify polyisoprenes into polyelectrolytes. This route has the advantage that membranes can be cast from a neutral intermediate polymer. The formation of membrane structure with this neutral product seems to be important with respect to physical and chemical crosslinking and the preparation of coagulated (porous) cation exchange membranes. Afterwards, sulfonate groups were introduced in the membrane by reaction with ammonia.

Homogeneous cation exchange membranes, prepared from an SIS block copolymer, could reject $\mathrm{NaCl}$ as well as $\mathrm{Na}_{2} \mathrm{SO}_{4}$ up to $82 \%$. Permeation and hyperfiltration experiments showed that the flux is primarily determined by the weight fraction of membrane water, $H$, during operation. The actual value of $H$ depends both on the applied pressure and on the salt concentration in the feed.

The most stable membranes were made from SISS-20 polymer prepared at a reaction temperature of $0^{\circ} \mathrm{C}$. 


\section{Nomenclature}

$a$

$B \quad$ constant

$C_{\text {feed }}$

$C_{\text {permeate }}$

$C^{*}$

$C_{d}^{*}$

$H$

$H^{*}$

$H_{0}$

$J_{w}$

$K_{i}$

$l$

$P$

$p$

$R_{\text {obs }}$

$x$

$z$ (\%) water)

constants

fraction of isoprene units in the polymer having a charged group

salt concentration in the feed solution (mole/l.)

salt concentration in the permeate (mole/l.)

effective charge density in the membrane (meq/g membrane

ion exchange capacity (meq/g dry polymer)

volume fraction of water in the membrane

weight fraction of water in the membrane

volume fraction of water in the membrane at $p=1 \mathrm{~atm}$

water flux through the membrane $\left(\mathrm{cm}^{3} / \mathrm{cm}^{2} \cdot \mathrm{hr}\right)$

membrane thickness $(\mathrm{cm})$

permeation coefficient $\left(\mathrm{cm}^{2} / \mathrm{sec} \cdot \mathrm{cm} \mathrm{Hg}\right)$

applied pressure (atm or $\mathrm{cm} \mathrm{Hg}$ )

observed rejection (\%)

ratio of moles $\mathrm{N}$-chlorosulfonyl isocyanate added to moles of iso-

prene present in the polymer (\%)

charge of coion

Greek Symbols

$\Delta \quad$ fraction of deswelling of the membrane $\left(=K_{2} p / H_{0}\right)$

$\Gamma \quad \gamma_{ \pm}^{*} / \gamma_{0}$

$\gamma_{ \pm}^{*} \quad$ mean ionic activity coefficient of salt in the membrane

$\gamma_{ \pm} \quad$ mean ionic activity coefficient of salt in the salt solution

$\Delta \pi \quad$ osmotic pressure difference across the membrane (atm)

\section{References}

1. A. J. Shor, K. A. Kraus, W. T. Smith, Jr., and J. S. Johnson, Jr., J. Phys. Chem., 72, 2200 (1968).

2. F. Hellfrich, Ion Exchange, McGraw-Hill, New York, 1962.

3. T. Yamabe, K. Umezawa, Sh. Yoshida, and N. Takai, Desalination, 15, 127 (1974).

4. C. W. Plummer, G. Kimura, and A. B. La Conti, Office of Saline Water R \& D Report No. 551, 1970.

5. P. J. Chludinski, J. F. Austin, and J. Enos, Office of Saline Water R \& D Report No. 697, 1971.

6. G. Lopatin and H. A. Newey, Office of Saline Water R \& D Report No. 690, 1971.

7. H. Yasuda and A. Schindler, in Reverse Osmosis Membrane Research, H. K. Lonsdale and H. E. Podall, Eds., Plenum Press, New York, 1972, pp. 299-316.

8. J. W. Van Heuven and R. K. Bloebaum, Desalination, 14, 229 (1974).

9. H. Yasuda, C. E. Lamaze, and A. Schindler, J. Polym. Sci. A-2, 9, 1579 (1971).

10. L. Van der Does, J. Hofman, and T. E. C. Van Utteren, J. Polym. Sci. B, 11, 169 (1973).

11. P. M. Van der Velden, M. H. V. Mulder, L. van der Does, and C. A. Smolders, J. Polym. Sci. B. 14, 5 (1976).

12. L. van der Does et al., to be published.

13. J. S. Johnson, Jr., in Reverse Osmosis Membrane Research, H. K. Lonsdale and H. E. Podall, Eds., Plenum Press, New York, 1972, pp. 379-404.

14. D. R. Paul and O. M. Ebra-Lima, J. Appl. Polym. Sci., 14, 2201 (1970). 
15. D. R. Paul and O. M. Ebra-Lima, J. Appl. Polym. Sci., 15, 2199 (1971).

16. H. Yasuda, C. E. Lamaze and A. Peterlin, J. Polym. Sci. A-2, 9, 1117 (1971).

17. A. Peterlin, H. Yasuda, and H. G. Olf, J. Appl. Polym. Sci., 16, 865 (1972).

18. A. Katchalski, S. Lifson, and H. Eisenberg, J. Polym. Sci., 7, 571 (1951); A. Katchalski et al., J. Polym. Sci. 8, 476 (1952).

19. H. Strathmann, Chem.-Ing.-Techn., 44, 1160 (1972).

20. D. G. Thomas, Ind. Eng. Chem., Fundam., 11, 302 (1972).

Received December 10, 1975

Revised February 18, 1976 